\title{
The survival effect of ovary preservation in early stage endometrial cancer: a single institution retrospective analysis
}

\author{
Wonkyo Shin ${ }^{1}$, Sang-Yoon Park ${ }^{1,2}$, Sokbom Kang ${ }^{1,3,4}$, Myong Cheol Lim ${ }^{1,4,5,6}$ and Sang-Soo Seo ${ }^{1 *}$ (D)
}

\begin{abstract}
Purpose: We investigated the effect of ovary preserving surgery in early International Federation of Obstetrics and Gynecology (FIGO) stage endometrial cancer patients.

Methods: Medical records were retrospectively reviewed for 539 patients who were diagnosed with early stage endometrial cancer between Jan 2006 and Dec 2017. Patients were categorized into ovary preservation and ovary removal groups. Demographics, recurrence free survival (RFS), and five-year overall survival (OS) rate were compared, and the clinical factors affecting survival were evaluated by univariate and multivariate analysis.

Results: The median follow-up period was 85 months (range, 6-142 months), and the median age was 52.7 years. The mean age was higher in the ovary removal group than in the ovary preservation group ( 54.4 vs 40.94 years; $P<$ $0.001)$. The ovary preservation group showed an earlier FIGO stage than the ovary removal group $(P=0.0264)$. There was a greater incidence of adjuvant chemotherapy administration in the removal group. There were no statistical differences in other baseline characteristics. When comparing the RFS and OS rates, there were no statistical differences between the preservation and removal groups. (recurrence free rate $98.5 \%$ vs $92.7 \%, p=0.4360$, and 5year survival rate $98.6 \%$ vs $93.0 \%, p=0.0892$, respectively). Endometrioid histology $(p=0.006)$ and post-operative adjuvant chemotherapy ( $p=0.0062)$ were related to OS, and adjuvant chemotherapy $(p<0.001)$ and radiotherapy $(p=0.005)$ were related to RFS.
\end{abstract}

Conclusions: Ovary preservation in early stage endometrial cancer is worth considering, as it does not affect survival in early stage endometrial cancer patients.

Keywords: Endometrial cancer, Early stage, Ovary preservation, Menopause

\section{Background}

Endometrial cancer has the highest incidence in gynecological cancers in Western countries [1], and the incidence is also increasing in Korea [2]. Conversely, endometrial cancer has a higher rate of early diagnosis than other gynecologic and solid cancers because symptoms such as irregular bleeding or discharge are easily detected

\footnotetext{
* Correspondence: ssseomd@ncc.re.kr

${ }^{1}$ Center for Gynecologic Cancer, Graduate School of Cancer Science and Policy, National Cancer Center, 323 Ilsan-ro, Ilsandong-gu, Goyang-si, Gyeonggi-do 10408, Republic of Korea

Full list of author information is available at the end of the article
}

by patients and diagnosis is possible with a simple endometrial curettage or hysteroscopic endometrial biopsy [3].

According to the National Comprehensive Cancer Network (NCCN) guidelines, early stage endometrial cancer is treated with total hysterectomy, bilateral salpingooophorectomy, and lymph node dissection, with subsequent staging according to the pathologic report. Adjunctive total salpingo-oophorectomy is the standard treatment option, because of the possibility of occult tumor cells in the ovary and the fact that endometrial cancer is advanced by ovarian hormones $[4,5]$. The incidence of ovarian tumors in 
patients with endometrial cancer is as 7\% [6]. However, surgical menopause caused by removing the ovaries can induce other complications, such as hot flushes, night sweats, vaginal dryness, insomnia, osteoporosis, cardiovascular problem, sexual dysfunction, and cognitive problems that can affect survival and quality of life [7-11]. Exogenous hormone replacement therapy may relieve these menopausal symptoms but can also induce other complications [12, 13].

Meta-analysis [14] and other research $[4,5,15,16]$ on ovarian preservation surgery in young, premenopausal early stage endometrial cancer patients has produced conflicting results. Some studies claim that it is safer to remove the ovaries, although preservation of the ovary generally does not affect patient recurrence or survival. However, in some meta-analyses and reviews, much of the patient data $(34.9 \%)$ is too old records [4], therefore, there is a risk of inaccurate medical records. Further, studies included incidentally diagnosed cancer patients who were regarded as having benign disease such as leiomyoma or adenomyosis prior to surgery, and only had hysterectomy planned without salpingo-oophorectomy.

In addition, many patients receive adjuvant treatment such as radiotherapy or chemotherapy after ovarian preserving surgery, which can further damage ovarian functions. These cases do not represent true ovarian preservation or help to reduce the complications of surgical menopause.

This retrospective study compares the survival of early International Federation of Obstetrics and Gynecology (FIGO) stage endometrial cancer patients who have the ovaries preserved with those who had the ovaries removed in a real clinical setting.

\section{Methods}

Medical records of patients with endometrial cancer who were newly diagnosed by endometrial biopsy and treated at
National Cancer Center in South Korea between January 2006 and December 2017 were reviewed. A total of 1578 endometrial cancer patients visited our outpatient clinics; however, 497 patients visited only once for counseling or a second opinion, and 439 patients had recurrent disease. Another 103 patients were excluded due to advanced cancer status (FIGO stage III or IV), which resulted in 539 patients who had been diagnosed and treated in our center for early (FIGO stage I or II) endometrial cancer (Fig. 1). Clinical factors including age at diagnosis, FIGO stage, FIGO grade, histology of the surgically removed tissues, surgical approach method, radicality of hysterectomy, lymph node dissection, and adjuvant chemotherapy and radiotherapy were collected.

Correlations of variables were assessed using the Fisher's exact or Student $t$-test. Five year overall survival (OS) rates and recurrence free survival (RFS) rates were estimated by Kaplan-Meier analysis. The log-rank test was used to compare survival curves. Cox regression analysis was performed to determine the predictive factors for prognosis with hazard ratios (HRs). $P$ values $<.05$ were considered to be significant. This retrospective study was approved by the institutional review board of our institution (IRB No. NCC2019-0272).

\section{Results}

The 539 patients included 469 in the ovarian removal group and 70 in the ovarian preservation group. The ovarian removal group was significantly older than the ovarian preservation group $(P<0.001)$. The FIGO stage was earlier in the ovarian preservation group $(P=0.0264)$. Lymph node dissection was more frequently performed in the ovarian removal group. There was no significant difference between the two groups in terms of surgical approach method, radicality of hysterectomy, or the administration of adjuvant

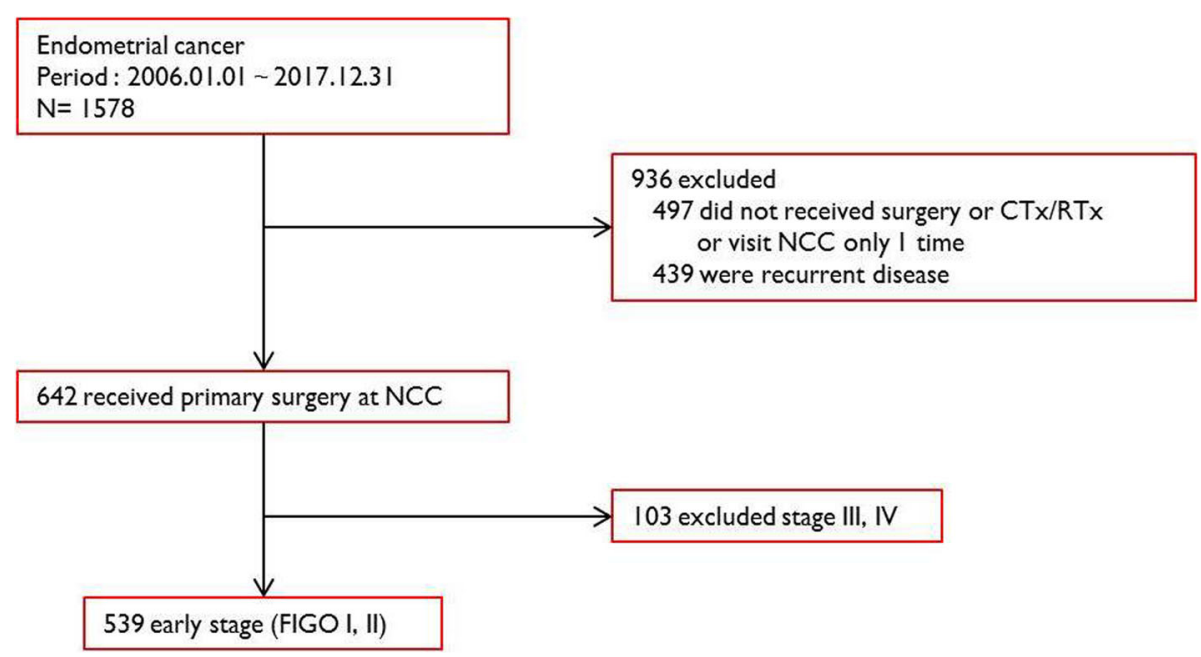

Fig. 1 Study flow chart 
chemotherapy or radiotherapy (Table 1). The five-year OS) and RFS) graphs showed no significant differences between ovarian preservation and removal groups (OS: 98.6\% vs.
93.0\%, $P=0.0892$, and RFS: $98.5 \%$ vs $92.7 \%, P=0.436$, respectively) (Fig. 2). Adjusted univariate analysis was performed for FIGO stage and patient age. Univariate analysis

Table 1 Patient baseline characteristics

\begin{tabular}{|c|c|c|c|c|}
\hline \multirow[t]{2}{*}{ Variables } & \multirow{2}{*}{$\begin{array}{l}\text { Total } \\
\boldsymbol{N}=539\end{array}$} & \multirow{2}{*}{$\begin{array}{l}\text { Ovary Preserved } \\
\boldsymbol{N}=70\end{array}$} & \multicolumn{2}{|l|}{ Ovary Removed } \\
\hline & & & $\boldsymbol{N}=469$ & $\boldsymbol{P}$-value \\
\hline \multicolumn{5}{|l|}{ FIGO Stage } \\
\hline IA & $390(72.36)$ & $60(85.71)$ & $330(70.36)$ & \multirow[t]{3}{*}{0.0264} \\
\hline $\mathrm{IB}$ & $126(23.38)$ & $8(11.43)$ & $118(25.16)$ & \\
\hline$\|$ & $23(4.27)$ & $2(2.86)$ & $21(4.48)$ & \\
\hline \multicolumn{5}{|l|}{ FIGO grade } \\
\hline 1 & $293(54.36)$ & $41(58.57)$ & $252(53.73)$ & \multirow[t]{4}{*}{0.289} \\
\hline 2 & $141(26.16)$ & $21(30)$ & $120(25.59)$ & \\
\hline 3 & $52(9.65)$ & $5(7.14)$ & $47(10.02)$ & \\
\hline Etc. & $53(9.83)$ & $3(4.29)$ & $50(10.66)$ & \\
\hline \multicolumn{5}{|l|}{ Histology } \\
\hline Endometrioid & $461(85.53)$ & $66(94.29)$ & $395(84.22)$ & \multirow[t]{4}{*}{0.2329} \\
\hline Serous & $31(5.75)$ & $2(2.86)$ & $29(6.18)$ & \\
\hline CCC & $20(3.71)$ & $1(1.43)$ & $19(4.05)$ & \\
\hline Mucinous/mixed/Undifferentiated/NE/etc. & $27(5.01)$ & $1(1.43)$ & $26(5.54)$ & \\
\hline \multicolumn{5}{|l|}{ Age (year) } \\
\hline mean $\pm S D$ & $52.68 \pm 10.42$ & $40.94 \pm 9.56$ & $54.43 \pm 9.36$ & $<.0001$ \\
\hline$<30$ & $11(2.04)$ & $8(11.43)$ & $3(0.64)$ & \multirow[t]{5}{*}{$<.0001$} \\
\hline $31 \sim 35$ & $19(3.53)$ & $13(18.57)$ & $6(1.28)$ & \\
\hline $36 \sim 40$ & $39(7.24)$ & $21(30)$ & $18(3.84)$ & \\
\hline $40 \sim 45$ & $51(9.46)$ & $11(15.71)$ & $40(8.53)$ & \\
\hline $45>$ & 419 (77.74) & $17(24.29)$ & $402(85.71)$ & \\
\hline \multicolumn{5}{|l|}{ Approach } \\
\hline Laparoscopy & $395(73.28)$ & $60(85.71)$ & $335(71.43)$ & \multirow[t]{3}{*}{0.0366} \\
\hline Laparotomy & $138(25.6)$ & $10(14.29)$ & $128(27.29)$ & \\
\hline Etc. & $6(1.11)$ & $0(0)$ & $6(1.28)$ & \\
\hline \multicolumn{5}{|l|}{ Hysterectomy - radicality } \\
\hline A & 489 (90.72) & $63(90)$ & $426(90.83)$ & \multirow[t]{4}{*}{0.7491} \\
\hline B & $18(3.34)$ & $2(2.86)$ & $16(3.41)$ & \\
\hline C & $27(5.01)$ & $5(7.14)$ & $22(4.69)$ & \\
\hline Not done & $5(0.93)$ & $0(0)$ & $5(1.07)$ & \\
\hline \multicolumn{5}{|l|}{ PLND } \\
\hline No & 112 (20.78) & $23(32.86)$ & 89 (18.98) & \multirow[t]{2}{*}{0.0076} \\
\hline Yes & $427(79.22)$ & $47(67.14)$ & 380 (81.02) & \\
\hline \multicolumn{5}{|l|}{ PALND } \\
\hline No & $251(46.57)$ & $51(72.86)$ & $200(42.64)$ & \multirow[t]{2}{*}{$<.0001$} \\
\hline Yes & $288(53.43)$ & $19(27.14)$ & $269(57.36)$ & \\
\hline \multicolumn{5}{|l|}{ Adjuvant Chemotherapy } \\
\hline No & 455 (84.42) & $66(94.29)$ & 389 (82.94) & \multirow[t]{2}{*}{0.0147} \\
\hline Yes & $84(15.58)$ & $4(5.71)$ & $80(17.06)$ & \\
\hline \multicolumn{5}{|l|}{ Adjuvant radiotherapy } \\
\hline No & 468 (86.83) & $64(91.43)$ & 404 (86.14) & \multirow[t]{2}{*}{0.2224} \\
\hline Yes & $71(13.17)$ & $6(8.57)$ & 65 (13.86) & \\
\hline
\end{tabular}

CCC clear cell carcinoma, NE neuroendocrine tumor, PLND pelvic lymph node dissection, PALND para-aortic lymph node dissection 


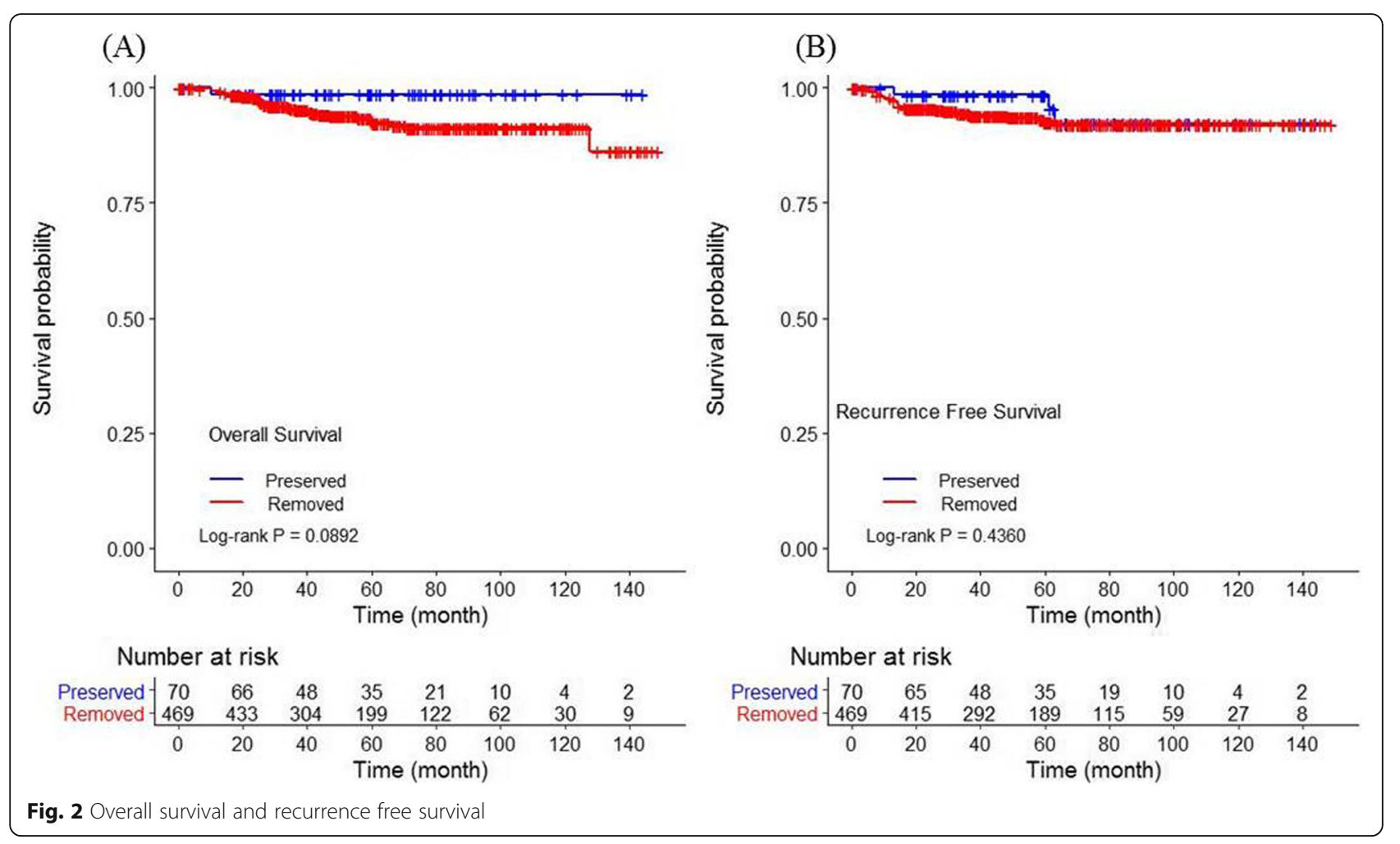

demonstrated that FIGO grade, histology, and adjuvant chemotherapy were significantly related to RFS and OS. Adjuvant radiotherapy was related to RFS only. Pelvic lymph node dissection was related to OS only. Neither surgical approach nor radicality of hysterectomy were related to RFS or OS. In multivariate analysis, histology and adjuvant chemotherapy were related to OS, and adjuvant chemotherapy and radiotherapy were related to RFS (Table 2). Compared to endometrioid histology, nonendometrioid histology showed relatively low RFS and OS. Ovarian preservation or removal was not related to RFS or OS.

\section{Discussion}

There is no clear consensus on the surgery scale in early stage endometrial cancer patients. Traditionally, total hysterectomy, bilateral salpingo-oophorectomy, and lymph node dissection and omentectomy for staging have been performed. According to the NCCN; American Society of Clinical Oncology (ASCO); and European Society for Medical Oncology, European Society of Gynaecological Oncology, and European Society for Radiotherapy \& Oncology (ESMO-ESGO-ESTRO) guidelines $[3,17,18]$, ovarian preservation can be considered in pre-menopausal early stage endometrial cancer patients. While oophorectomy removes any occult ovarian metastatic tumor and reduces the ovarian cancer risk, surgical menopausal problems can result.
Previous studies have shown that preserving the ovary does not affect survival in patients with early stage endometrial cancer who are not menopausal, compared with those who have had the ovaries removed [4, 5, 14, 15]. Previous studies are compared in Table 3. These retrospective studies were conducted in the United States, China, and Korea, conducted mainly with pre-menopausal women as patient groups. Prospective research has been difficult to perform as recruitment of early stage and premenopausal patients has been challenging. Their results showed that in the case of early stage and low FIGO grade, preservation of the ovary did not affect the prognosis of the patient. Recently, a systemic review summarized previous studies, with more than 10,000 cases, and revealed an increase in OS and no shortening of RFS. In the early stages of premenopausal women, ovarian preservation may be a viable treatment option [19]. The results are similar to ours. However, as previously noted, this research has several limitations, including a large portion of patients with benign disease, the inclusion of patients with adjuvant chemotherapy or radiotherapy after preserving the ovaries $[5,16]$, or including patients with old records [4]. There are many reports of ovarian function deterioration after radiation or chemotherapy in premenopausal women [20-23]. These cases demonstrate that preserving the ovaries does not result in 
Table 2 Univariate and multivariate analysis of prognostic factors

\begin{tabular}{|c|c|c|c|c|c|c|c|c|}
\hline \multirow[t]{4}{*}{ variables } & \multicolumn{4}{|l|}{ Overall survival } & \multicolumn{4}{|c|}{ Recurrence Free survival } \\
\hline & \multicolumn{2}{|l|}{ Adjusted model $^{\mathbf{a}}$} & \multicolumn{2}{|l|}{ Multivariable $^{\mathbf{b}}$} & \multicolumn{2}{|c|}{ Adjusted model $^{\mathbf{a}}$} & \multicolumn{2}{|l|}{ Multivariable $^{\mathbf{b}}$} \\
\hline & \multicolumn{2}{|l|}{$\mathrm{HR}(95 \% \mathrm{Cl})$} & \multicolumn{2}{|l|}{$\mathrm{HR}(95 \% \mathrm{Cl})$} & \multicolumn{2}{|l|}{$\mathrm{HR}(95 \% \mathrm{Cl})$} & \multicolumn{2}{|l|}{$\mathrm{HR}(95 \% \mathrm{Cl})$} \\
\hline & $N=539 /$ EVNET $=31$ & $p$-value & $N=539 /$ EVNET $=31$ & $p$-value & $N=539 / E V N E T=33$ & $p$-value & $\begin{array}{l}N=539 / \\
E V N E T=33\end{array}$ & $p$-value \\
\hline \multicolumn{9}{|l|}{ Ovary } \\
\hline preserved & 1 (ref) & & & & 1 (ref) & & & \\
\hline removed & $2.058(0.266-15.915)$ & 0.4892 & & & $0.865(0.245-3.052)$ & 0.8215 & & \\
\hline \multicolumn{9}{|l|}{ FIGO grade } \\
\hline 1 & 1 (ref) & 0.0103 & & & 1 (ref) & 0.0339 & & \\
\hline 2 & 2.305 (0.869-6.116) & 0.0935 & & & $2.418(1.052-5.556)$ & 0.0376 & & \\
\hline 3 & 4.215 (1.324-13.42) & 0.0149 & & & $1.176(0.255-5.416)$ & 0.8355 & & \\
\hline etc & $5.102(1.838-14.162)$ & 0.0018 & & & 3.807 (1.465-9.894) & 0.0061 & & \\
\hline \multicolumn{9}{|l|}{ Histology } \\
\hline Endometrioid & 1 (ref) & 0.0013 & 1 (ref) & 0.0006 & 1 (ref) & 0.0322 & & \\
\hline Serous & $5.333(2.206-12.892)$ & 0.0002 & 5.969 (2.437-14.617) & $<.0001$ & 3.548 (1.389-9.062) & 0.0081 & & \\
\hline $\mathrm{CCC}$ & $3.381(0.968-11.806)$ & 0.0562 & 3.729 (1.064-13.072) & 0.0397 & $3.031(0.894-10.274)$ & 0.075 & & \\
\hline $\begin{array}{l}\text { Mucinous/mixed/ } \\
\text { Undifferentiated/NE/etc }\end{array}$ & $3.212(0.921-11.196)$ & 0.067 & $3.373(0.963-11.808)$ & 0.0572 & 1.609 (0.374-6.918) & 0.5224 & & \\
\hline \multicolumn{9}{|l|}{ approach } \\
\hline Laparoscopy & 1 (ref) & 0.027 & & & 1 (ref) & 0.4568 & & \\
\hline Laparotomy & $2.298(1.058-4.992)$ & 0.0355 & & & $1.604(0.765-3.36)$ & 0.2106 & & \\
\hline etc & $7.88(0.974-63.726)$ & 0.0529 & & & - & 0.9883 & & \\
\hline \multicolumn{9}{|l|}{ Hysterectomy - radicality } \\
\hline A & 1 (ref) & 0.2591 & & & 1 (ref) & 0.9624 & & \\
\hline B & - & 0.9901 & & & $0.598(0.073-4.913)$ & 0.6322 & & \\
\hline C & $0.443(0.091-2.159)$ & 0.3139 & & & $0.776(0.162-3.704)$ & 0.7503 & & \\
\hline Not done & $6.183(0.769-49.733)$ & 0.0868 & & & - & 0.9887 & & \\
\hline \multicolumn{9}{|l|}{ PLND } \\
\hline No & 1 (ref) & & & & 1 (ref) & & & \\
\hline Yes & $0.371(0.162-0.852)$ & 0.0194 & & & $0.549(0.24-1.256)$ & 0.1556 & & \\
\hline \multicolumn{9}{|l|}{ PALND } \\
\hline No & 1 (ref) & & & & 1 (ref) & & & \\
\hline Yes & $0.848(0.407-1.766)$ & 0.6593 & & & $1.008(0.491-2.068)$ & 0.9826 & & \\
\hline \multicolumn{9}{|l|}{ Adjuvant chemotherapy } \\
\hline No & 1 (ref) & & 1 (ref) & & 1 (ref) & & 1 (ref) & \\
\hline Yes & $2.083(0.969-4.477)$ & 0.0602 & $0.318(0.137-0.736)$ & 0.0074 & $2.864(1.396-5.873)$ & 0.0041 & 3.414 (1.649-7.069) & 0.0009 \\
\hline \multicolumn{9}{|l|}{ Adjuvant radiotherapy } \\
\hline No & 1 (ref) & & & & 1 (ref) & & 1 (ref) & \\
\hline Yes & $0.659(0.249-1.744)$ & 0.4006 & & & $2.655(1.163-6.059)$ & 0.0204 & $3.256(1.428-7.423)$ & 0.005 \\
\hline
\end{tabular}

CCC clear cell carcinoma, NE neuroendocrine tumor, PLND pelvic lymph-node dissection, PALND para-aortic lymph node dissection

${ }^{a}$ Adjusted model: adjuted age at diagnosis ( $\leq 50$ vs $>50$ ), FIGO stage

${ }^{\mathrm{b}}$ Multivariableb: adjuted age at diagnosis ( $\left.\leq 50 \mathrm{vs}>50\right)$, FIGO stage

maintaining ovarian function, since adjuvant treatment can also induce menopause.

Endometrial cancer in premenopausal women has been shown to be hormone related, have early stage, no myometrial invasion, and good prognosis [24]. If metastatic or synchronous malignancy has not been found in the ovary during surgery, ovarian preservation may be performed; therefore, surgical menopause of the patient 
Table 3 Previous studies about ovarian preservation in endometrial cancer patients

\begin{tabular}{|c|c|c|c|c|c|c|c|c|c|c|}
\hline Study & Year & Country & Period & Patients & Age & Stage & Grade & Histology & $\begin{array}{l}\text { Follow up } \\
\text { period (month) }\end{array}$ & $\begin{array}{l}\text { Survival } \\
\text { benefits }\end{array}$ \\
\hline Wright & 2009 & USA & 1988-2004 & $402 / 2867$ & 45 & la $64 \%$, lb $33 \%$, lc $3 \%$ & | 79\%, || 14\%, ||| 3\% & endo & $1-121$ & NS \\
\hline Lee & 2009 & Korea & 1993-2005 & $123 /-$ & 45 & la $74 \%$, lb $23 \%$, lc $3 \%$ & | 70\%, || 17\%, ||| 2\% & Endo $(86 \%)$ & $1-125$ & $\begin{array}{l}\text { No recur, } \\
\text { 5-yr OS:98\% }\end{array}$ \\
\hline Sun & 2012 & China & 2002-2010 & $34 / 132$ & 45 & la $71 \%$, lb $22 \%$, lc $7 \%$ & | 70\%, || 20\%, ||| 10\% & Endo (97\%) & $27-122$ & NS \\
\hline Lee & 2013 & Korea & 1997-2008 & $176 / 319$ & & la $89 \%$ lb 5\% || 6\% & | 78\% || 18\% ||| 4\% & endo & $6-208$ & NS \\
\hline Wright & 2016 & USA & 1998-2012 & $1121 / 14527$ & $<50$ & la $89 \%$ lb $8 \%$ || 3\% & | 60\% || 27\% ||| 6\% & endo & 61, median & NS \\
\hline Wang & 2016 & China & 2009-2015 & $25 / 76$ & $<45$ & la $87 \%$, lb 13\% & | 75\%, || 21\%, ||| 40\% & Endo (99\%) & & NS \\
\hline
\end{tabular}

NS non-specific

is not induced, which may be more beneficial to women's health. We recommend to consider the pathology of the tumor and the necessity of maintaining fertility before surgery.

Although this retrospective study has some limitations, this is the first study in which all patients had been diagnosed with endometrial cancer through preoperative endometrial biopsy, and had ovarian preservation or removal planned in advance of surgery, after confirming no other distant metastasis through computed tomography scan and lab test. Further, a relatively low ratio of patients was administered adjuvant treatment, so this study may serve as a reliable reference for early FIGO stage endometrial cancer. However, this study has limited data about the side effects of each group, especially menopausal problems that occur in the ovarian removal group. Long-term follow-up of adverse effects in postoperative patients may reveal significant differences in patients who have undergone surgical menopause. Second, although a small number of patients received adjuvant treatment after surgery, that treatment was related to survival; consequently, a more accurate group selection process is warranted for future studies.

Cancer survival and life expectancy after diagnosis are increasing, and quality of life issues are becoming more important. It is time forFurther prospective research to confirm whether it is more favorable to remove the ovaries to decrease risk of recurrence or to maintain patient quality of life through ovarian preservation.

\section{Conclusions}

Ovarian preserving surgery in early stage endometrial cancer is a beneficial option for premenopausal patients and is not related to disease recurrence or overall survival rate. More precise stratification analysis is needed to determine which additional groups may safely preserve the ovary.

\section{Abbreviations}

ASCO: American Society of Clinical Oncology; ESMO-ESGO-ESTRO: European Society for Medical Oncology, European Society of Gynaecological Oncology, and European Society for Radiotherapy \& Oncology; FIGO: International Federation of Obstetrics and Gynecology; HRs: Hazard ratios; IRB: Institutional review board of our institution; NCCN: National Comprehensive Cancer Network; RFS: Recurrence free survival; OS: Overall survival
Acknowledgements

Not applicable.

\section{Authors' contributions}

Conceptualization: Wonkyo Shin, Sangsoo Seo. Data analysis: Wonkyo Shin. Manuscript draft: Wonkyo Shin. Manuscript revision and review: Myongcheol Lim, Sangyoon Park, Sokbom Kang. Supervision: Sangsoo Seo. The author(s) read and approved the final manuscript.

Funding

Not applicable.

\section{Availability of data and materials}

All data generated or analysedanalyzed during this study are included in this published article.

Ethics approval and consent to participate

This retrospective study was approved by the institutional review board of our institution (IRB No. NCC2019-0272).

Consent for publication

Not applicable.

\section{Competing interests}

The authors declare that they have no competing interests.

\section{Author details}

${ }^{1}$ Center for Gynecologic Cancer, Graduate School of Cancer Science and Policy, National Cancer Center, 323 IIsan-ro, Ilsandong-gu, Goyang-si, Gyeonggi-do 10408, Republic of Korea. ${ }^{2}$ Common Cancer Branch, Research Institute Graduate School of Cancer Science and Policy, National Cancer Center, Goyang, Republic of Korea. ${ }^{3}$ Precision Medicine Branch, Graduate School of Cancer Science and Policy, National Cancer Center, Goyang, Republic of Korea. ${ }^{4}$ Department of Cancer Control \& Population Health, Graduate School of Cancer Science and Policy, National Cancer Center, Goyang, Republic of Korea. ${ }^{5}$ Center for Clinical Trials, Graduate School of Cancer Science and Policy, National Cancer Center, Goyang, Republic of Korea. ${ }^{6}$ Cancer Healthcare Research Branch, Graduate School of Cancer Science and Policy, National Cancer Center, Goyang, Republic of Korea.

Received: 1 May 2020 Accepted: 3 August 2020

Published online: 22 August 2020

\section{References}

1. Siegel RL, Miller KD, Jemal A. Cancer statistics, 2017. CA Cancer J Clin. 2017;67:7-30.

2. Lim MC, Won YJ, Ko MJ, Kim M, Shim SH, Suh DH, et al. Incidence of cervical, endometrial, and ovarian cancer in Korea during 1999-2015. J Gynecol Oncol. 2019;30:e38.

3. Colombo N, Creutzberg N, Amant F, Bosse T, González-Martín A, Ledermann J, Marth C, Nout R, Querleu D, Mirza MR, Sessa C, ESMO-ESGOESTRO Endometrial Consensus Conference Working Group. ESMO-ESGO-ESTRO Consensus Conference on Endometrial Cancer: diagnosis, treatment and follow-up. Ann Oncol. 2016;27(1):16-41. https://doi.org/10.1093/annonc/ $\mathrm{mdv} 484$. 
4. Wright JD, Buck AM, Shah M, Burke WM, Schiff PB, Herzog TJ. Safety of ovarian preservation in premenopausal women with endometrial cancer. $J$ Clin Oncol. 2009:27:1214-9.

5. Wright JD, Jorge S, Tergas Al, Hou JY, Burke WM, Huang Y, et al. Utilization and outcomes of ovarian conservation in premenopausal women with endometrial cancer. Obstet Gynecol. 2016;127:101-8.

6. Lee TS, Jung JY, Kim JW, Park NH, Song YS, Kang SB, et al. Feasibility of ovarian preservation in patients with early stage endometrial carcinoma. Gynecol Oncol. 2007;104:52-7.

7. Muka T, Oliver-Williams C, Kunutsor S, Laven JS, Fauser BC, Chowdhury R, et al. Association of age at onset of menopause and time since onset of menopause with cardiovascular outcomes, intermediate vascular traits, and all-cause mortality: a systematic review and meta-analysis. JAMA Cardiol. 2016;1:767-76.

8. Svejme O, Ahlborg HG, Nilsson JA, Karlsson MK. Early menopause and risk of osteoporosis, fracture and mortality: a 34-year prospective observational study in 390 women. BJOG. 2012;119:810-6.

9. Bove R, Secor E, Chibnik LB, Barnes LL, Schneider JA, Bennett DA, et al. Age at surgical menopause influences cognitive decline and Alzheimer pathology in older women. Neurology. 2014;82:222-9.

10. Doganay M, Kokanali D, Kokanali MK, Cavkaytar S, Aksakal OS. Comparison of female sexual function in women who underwent abdominal or vaginal hysterectomy with or without bilateral salpingo-oophorectomy. J Gynecol Obstet Hum Reprod. 2019;48:29-32.

11. Secosan C, Balint O, Pirtea L, Grigoras D, Balulescu L, llina R. Surgically induced menopause-a practical review of literature. Medicina (Kaunas). 2019:55(8):482 https://doi.org/10.3390/medicina55080482.

12. Edey KA, Rundle S, Hickey M. Hormone replacement therapy for women previously treated for endometrial cancer. Cochrane Database Syst Rev. 2018;5:CD008830.

13. Sullivan SD, Sarrel PM, Nelson LM. Hormone replacement therapy in young women with primary ovarian insufficiency and early menopause. Fertil Steril. 2016;106:1588-99.

14. Sun C, Chen G, Yang Z, Jiang J, Yang X, Li N, et al. Safety of ovarian preservation in young patients with early-stage endometrial cancer: a retrospective study and meta-analysis. Fertil Steril. 2013;100:782-7.

15. Lee TS, Kim JW, Kim TJ, Cho CH, Ryu SY, Ryu HS, et al. Ovarian preservation during the surgical treatment of early stage endometrial cancer: a nationwide study conducted by the Korean gynecologic oncology group. Gynecol Oncol. 2009;115:26-31

16. Lee TS, Lee JY, Kim JW, Oh S, Seong SJ, Lee JM, et al. Outcomes of ovarian preservation in a cohort of premenopausal women with early-stage endometrial cancer: a Korean gynecologic oncology group study. Gynecol Oncol. 2013;131:289-93.

17. Koh WJ, Abu-Rustum NR, Bean S, Bradley K, Campos SM, Cho KR, et al. Uterine neoplasms, version 1.2018, NCCN clinical practice guidelines in oncology. J Natl Compr Cancer Netw. 2018;16:170-99.

18. Oktay K, Harvey BE, Partridge AH, Quinn GP, Reinecke J, Taylor HS, et al. Fertility preservation in patients with cancer: ASCO clinical practice guideline update. J Clin Oncol. 2018;36:1994-2001.

19. Jia P, Zhang Y. Ovarian preservation improves overall survival in young patients with early-stage endometrial cancer. Oncotarget. 2017;8:59940-9.

20. Rosendahl M, Andersen CY, la Cour FN, Juul A, Lossl K, Andersen AN. Dynamics and mechanisms of chemotherapy-induced ovarian follicular depletion in women of fertile age. Fertil Steril. 2010;94:156-66.

21. Chemaitilly W, Li Z, Krasin MJ, Brooke RJ, Wilson CL, Green DM, et al. Premature ovarian insufficiency in childhood cancer survivors: a report from the St. Jude lifetime cohort. J Clin Endocrinol Metab. 2017;102(7):2242-50. https://doi.org/10.1210/jc.2016-3723.

22. Levine JM, Whitton JA, Ginsberg JP, Green DM, Leisenring WM, Stovall M, et al. Nonsurgical premature menopause and reproductive implications in survivors of childhood cancer: a report from the childhood cancer survivor study. Cancer. 2018;124:1044-52.

23. van Dorp W, Haupt R, Anderson RA, Mulder RL, van den Heuvel-Eibrink MM, van Dulmen-den Broeder $E$, et al. Reproductive function and outcomes in female survivors of childhood, adolescent, and young adult cancer: a review. J Clin Oncol. 2018;36:2169-80

24. Carneiro MM, Lamaita RM, Ferreira MC, Silva-Filho AL. Fertility-preservation in endometrial cancer: is it safe? Review of the literature. JBRA Assist Reprod. 2016;20:232-9.

\section{Publisher's Note}

Springer Nature remains neutral with regard to jurisdictional claims in published maps and institutional affiliations.
Ready to submit your research? Choose BMC and benefit from:

- fast, convenient online submission

- thorough peer review by experienced researchers in your field

- rapid publication on acceptance

- support for research data, including large and complex data types

- gold Open Access which fosters wider collaboration and increased citations

- maximum visibility for your research: over $100 \mathrm{M}$ website views per year

At $\mathrm{BMC}$, research is always in progress.

Learn more biomedcentral.com/submissions 